\title{
The Analysis of 2D Crowd Behaviour Simulation during Emergency Situation
}

\author{
Hamizan Sharbini \\ Faculty of Com Science \& IT \\ Universiti Malaysia Sarawak \\ 94300 Kota Samarahan Sarawak \\ shamizan@unimas.my
}

\author{
Cheah Wai Shiang \\ Faculty of Com Science \& IT \\ Universiti Malaysia Sarawak \\ 94300 Kota Samarahan Sarawak \\ wscheah@unimas.my
}

\author{
Nur Aisyah binti Masrizal \\ Faculty of Com Science \& IT \\ Universiti Malaysia Sarawak \\ 94300 Kota Samarahan Sarawak \\ nuraisyahmasrizal@gmail.com
}

\author{
Azlina Ahmadi Julaihi \\ Faculty of Com Science \& IT \\ Universiti Malaysia Sarawak \\ 94300 Kota Samarahan Sarawak \\ ajazlina@unimas.my
}
Noor Alamshah Bolhassan
Faculty of Com Science \& IT
Universiti Malaysia Sarawak
94300 Kota Samarahan Sarawak
bnalamshah@unimas.my

\author{
Chiu Po Chan \\ Faculty of Com Science \& IT \\ Universiti Malaysia Sarawak \\ 94300 Kota Samarahan Sarawak \\ pcchiu@unimas.my
}

\author{
Tan Ping Ping \\ Faculty of Com Science \& IT \\ Universiti Malaysia Sarawak \\ 94300 Kota Samarahan Sarawak \\ pptan@unimas.my
}

\begin{abstract}
This paper will discuss about general crowd behaviour modeling during evacuation in emergency situation such as during fire breakout. Several existing simulation tools and comparison among each tool will also be discussed. The aim of this project is to develop a generic crowd model, which has the ability to demonstrate individual crowd behaviours (micro level) especially in fire emergency situation with one or more exits. The program will be able to estimate the evacuation time of panic situation during fire breakout. Apart from that, this paper also will analyze and prove that the individual agent in the simulation is able to detect and avoid collision. During panic situation, agents need to search for the exit in order to save themselves from danger. The proposed crowd simulation used agent in $2 \mathrm{D}$ as to simulate the crowd behaviour model while steering towards the exit.
\end{abstract}

\section{CCS Concepts}

Simulation and Modeling $\rightarrow$ Simulation Support Systems $\rightarrow$ Environments

\section{Keywords}

Crowd simulation; evacuation management; building architectural planning.

\section{INTRODUCTION}

Human crowd behaviour is a captivating social phenomenon in the

(C)2019 Association for Computing Machinery. ACM acknowledges that this contribution was authored or co-authored by an employee, contractor or affiliate of a national government. As such, the Government retains a nonexclusive, royalty-free right to publish or reproduce this article, or to allow others to do so, for Government purposes only.

ICIBE 2019, September 27-29, 2019, Hong Kong, Hong Kong

(C) 2019 Association for Computing Machinery. ACM ISBN 978-1-4503-76532/19/09...\$15.00

DOI: https://doi.org/10.1145/3364335.3365586

natural world. Therefore, crowd simulation has become significant research field especially in computer graphic, virtual reality, the social sciences and civil engineering. The purpose of the crowd simulation is to facilitate the understanding of the dynamics of a system and attempt to predict its future evolution. Modeling and simulation technologies have been gaining tremendous momentum in crowd dynamics research over the last few years. Various simulation architectures have been developed [1][2][3]; virtual environment representations have also been constructed for crowd simulations [4]. To represent the behaviour of crowd, a number of behaviour models have been proposed [5][6][7] with different types of modeling approaches such as flow-based models and agent-based models. In this project, we emphasis on the scenario of a fire emergency evacuation in a certain building. The aim of this project

is to predict and animate human crowd behaviour and movement when in emergency evacuation circumstances especially in fire emergency because it is hard to determine the path since the crowd can become irrational and uncontrolled. In this project, the model of the crowd will be put in a stress situation which is a fire emergency case; and the crowd model will attempt to rescue themselves to the safe exit by detecting incoming collision and obstacles. The outcome from this project will be presented in a realistic $2 \mathrm{D}$ animated environment that is similar to the real circumstance.

\section{LITERATURE REVIEW}

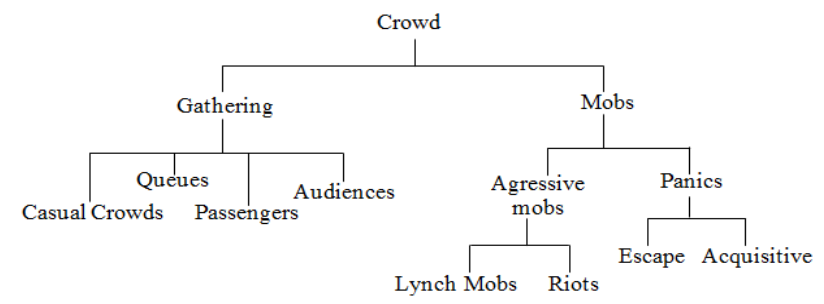

Figure 1. Classification of crowds [9]. 